\title{
UM CONTRIBUTO PARA O DEBATE SOBRE A REDEFINIÇÃO DA ESFERA PÚBLICA EM REDE A PARTIR DA PARTICIPAÇÃO PÚBLICA DOS PORTUGUESES NO CIBERESPAÇO
}

\author{
Tiago Lima Quintanilha
}

\begin{abstract}
Resumo
O presente artigo tenta enquadrar para Portugal a discussão sobre a transição de uma esfera pública normativa (Habermas, 1968/1989, 1998) para uma nova esfera pública em rede (Benkler, 2006), potenciada pelas características da internet, pela sociedade em rede global, e pelas culturas participativas e interativas. São utilizados dados do módulo participação pública do inquérito Digital news report, do Reuters Institute for the Study of Journalism, de 2018, aplicado a uma amostra representativa da população portuguesa. Os dados obtidos apontam para a existência e apropriação dos múltiplos formatos de participação pública no ciberespaço, através da partilha de notícias, comentários a notícias, participação em processos de votação online, etc., nos sites de títulos de imprensa ou nas redes sociais. Contudo, os dados coligidos apontam para a fundação de uma participação pública no ciberespaço que, pelas suas características, determina a constituição e consolidação lentas de uma nova esfera pública em rede para o contexto português.
\end{abstract} em rede; participação pública online; Portugal

\section{A CONTRIBUTION TO THE DEBATE ON THE REDEFINITION OF THE NETWORKED PUBLIC SPHERE BASED ON PORTUGUESE PUBLIC PARTICIPATION IN CYBERSPACE}

\begin{abstract}
This article locates Portugal in the discussion on the transition from a normative public sphere (Habermas, 1968/1989, 1998) to a new networked public sphere (Benkler, 2006), powered by the internet, global networked society and participative and interactive cultures. We use data from the public participation module of the 2018 Digital news report published by the Reuters Institute for the Study of Journalism, which surveyed a representative sample of the Portuguese population. The results point to the existence and appropriation of many forms of public participation in cyberspace. Users share news, comment on news, take part in online votes, etc., on press websites and social media. Nonetheless, the collected data point to a type of online public participation that determines the slow constitution and consolidation of a new networked public sphere in Portugal.
\end{abstract}

KEYWORDS

Seminal public sphere; redefinition of public sphere; networked public sphere; online public participation; Portugal 


\section{INTRODUÇÃo}

A transformação do paradigma dos meios de comunicação de massas acarreta mudanças assinaláveis em termos das práticas mediáticas e do papel do cidadão/consumidor/produtor. (Sousa, Pinto \& Costa e Silva, 2013, p. 5)

Com o advento dos não-mercados descentralizados de produção horizontal de conteúdos na internet (Benkler, 2006), e com a redefinição das fronteiras entre produtores e consumidores de informação, consubstanciada no 1) aparecimento das audiências interativas e participativas, e 2) do jornalismo em rede ou participativo (Beckett, 2008, 2010; Glasser, 1999, 2010; Noor, 2017; Rosen, 1999; Singer, 2012; Van der Haak et al., 2012), passa a fazer sentido reposicionar o debate sobre esfera pública no contexto da participação pública em rede, um debate que é simultaneamente global, no espectro das características da sociedade em rede, e local no âmbito das especificidades dos diferentes países.

"De difícil definição e complexa configuração" (Sousa et al., 2013, p. 5), a conceção original de Habermas (1968/1989) deu origem às "configurações mais contemporâneas que incluem uma ecologia mediática pontuada pela Internet" (Sousa et al., 2013, p. 5), que tem sido "apontada como instrumento de suporte às novas formas de envolvimento na vida pública" (Frenette \& Vermette, 2013, p. 15). Como mencionam Carvalho e Casanova (2010), a internet e as diversas modalidades de informação, interação e discussão, constituem um impulso renovador da esfera pública e das instâncias mediadoras da ordem democrática, numa opinião partilhada por Benkler (2006), Carlsson e Weibull (2018) que falam de um ambiente informativo em rede a operar fora da esfera de mercado, de forma descentralizada, com influência na redefinição e democratização da esfera pública.

\section{ESTRATÉGIA METODOLÓGICA}

A estratégia metodológica adotada na elaboração deste artigo privilegia o método quantitativo com o recurso a dados secundários coligidos pelo Reuters Institute for the Study of Journalism, num estudo designado por Digital news report 2018 (DNR) que resulta, para o caso português, de uma colaboração com o Observatório da Comunicação. Para a realização deste estudo, foram aplicados inquéritos online a uma amostra estratificada proporcional da população portuguesa, constituída por 2008 inquiridos distribuídos por Portugal Continental e regiões autónomas dos Açores e da Madeira. Esta amostra não é representativa da população utilizadora de internet mas sim da população portuguesa em geral.

O recurso aos dados secundários aqui utilizados é explicado por três razões principais: 1) pelo facto de o inquérito Digital news report, do Reuters Institute for the Study of Journalism, ser hoje, e desde 2015, o principal instrumento de recolha de dados sobre as experiências de relacionamento com notícias por parte dos utilizadores de internet em Portugal; 2) pelo facto de o inquérito "Sociedade em Rede em Portugal", importante exercício metodológico de recolha de informação sobre a atividade e experiências online 
dos portugueses não ter sido replicado após a última edição em dezembro de 2013; e 3) pela proximidade do autor do artigo ao Observatório da Comunicação de Lisboa, entidade que colabora com o Reuters Institute for the Study of Journalism na realização do projeto, gestão dos dados e divulgação do estudo em Portugal.

Por outro lado, uma das vantagens associadas ao uso dos dados mencionados, inseridos no módulo de participação online do DNR, explica-se precisamente pelo alcance do estudo de acordo com a sua representatividade, algo que, com a descontinuidade dos relatórios "A sociedade em rede", se constitui como uma mais-valia à tentativa de explorar novas dinâmicas de experiência online dos portugueses.

Relativamente ao uso do inquérito de natureza representativa, Bryman (2004, p. 11,2012, p. 192) lembra-nos que a sua principal vantagem reside na capacidade de gerar dados quantificáveis de uma população maior, permitindo uma aproximação às características da própria população.

\section{O ENQUADRAMENTO E DEBATE SOBRE A TEORIA NORMATIVA DE ESFERA PÚBLICA E A NOVA ESFERA PÚBLICA EM REDE.}

A conceção seminal de esfera pública de Habermas $(1968 / 1989,1998)$ descreve um espaço de instituições e práticas entre os interesses privados da vida quotidiana na sociedade civil e o domínio do poder do Estado. Habermas (1998) fala de um sistema de comunicação entre Estado e sociedade civil (Habermas, 1998), numa definição que é abraçada por autores como Gerhards e Neidhardt (1991) que aludem a um sistema comunicacional capaz de fazer a mediação entre cidadãos e sistema governativo. Neste processo de mediação, e segundo a abordagem normativa de esfera pública, vários autores (Ahva, 2011, p. 1; Walter, 2015) observam o papel determinante do jornalismo e dos jornalistas que definem o que é noticiado e quem participa na cobertura mediática.

A conceção de esfera pública do filósofo e sociólogo alemão Jürgen Habermas (1968/1989) contempla assim a ideia normativa de que sem o estímulo promovido pelo fluxo informativo apoiado na experiência e perícia capazes de garantir pesquisa intensiva (que não é um processo barato), a comunicação pública perde a sua vitalidade e o seu referencial, comprometendo os padrões da atividade jornalística e o coração da esfera pública. A visão de Habermas é portanto bastante próxima da teoria normativa do gatekeeping (Lewis, 2012; Manning, 1950; Shoemaker \& Vos, 2009; Singer, 2012), sugerindo de forma mais ou menos declarada a posição do jornalista enquanto gatekeeper de uma esfera pública singular.

Contudo, autores como Castells (2008), nas suas discussões sobre o papel do informacionalismo e da sociedade em rede como catalisadores de uma mudança fundamentalmente determinada pela tecnologia, alegam que o processo de globalização alargou o debate nacional para o debate global, promovendo o surgimento de uma sociedade civil transnacional e de formas ad hoc de governança global. Ao mesmo tempo, a esfera pública como espaço de debate sobre assuntos públicos também muda de uma dimensão nacional para uma dimensão transnacional construída nas redes de comunicação de alcance global. 
Para Benkler (2006), a ideia de que, na internet, os cidadãos passam a tirar partido de uma nova liberdade de agir e cooperar com o outro, redunda no entendimento de um melhoramento da experiência democrática, das condições de justiça e da reflexividade, com óbvios benefícios para as comunidades.

Benkler (2006), apesar de falar já de uma Era caracterizada pela sobrecarga informativa e pelos perigos resultantes da incapacidade de assimilar o fluxo de produção e disseminação informativas - Ninguém ouve quando todos falam! -, não conseguiu prever imediatamente os efeitos da desregulação desse híper-fluxo informativo, tendo por isso uma visão sobretudo otimista e celebratória da formulação de uma esfera pública em rede.

Para o autor, a construção de uma esfera pública em rede minimizaria de certa forma os condicionalismos e as limitações dos mass media - aquilo que Haas (2007) designou de falhas do jornalismo convencional -, exponenciando as formas segundo as quais qualquer pessoa passa a poder falar, a poder questionar e a poder investigar, tirando partido das características e do alcance da internet. Benkler (2006) valoriza assim a refundação de uma esfera pública em rede que se constrói nas abordagens descentralizadas capazes de cumprir a função de vigilância/watchdog, ao alargar o debate aos novos intervenientes e atores nas várias modalidades de produção horizontal de informação.

Para Hjarvard (2018, p. 72), que se aproxima das considerações celebratórias de Benkler (2006), esta nova esfera pública em rede surge como o processo de transformação estrutural da esfera pública habermasiana, onde os media em rede são responsáveis pela reestruturação das relações pessoais, privadas, e das arenas públicas, bem como de novas formas de comunicação mais deliberativas.

Khan (2012), por outro lado, ao situar-se no meio desta espécie de contenda entre esfera pública habermasiana e nova esfera pública em rede, refere que o enquadramento para a descrição da esfera pública de Habermas continua a ver os seus princípios e mecanismos fundadores como sendo ainda relevantes na teoria sobre a esfera pública global (Khan, 2012; Giddens, 2000). Para este autor, as características de uma nova esfera pública, como a globalização, os softwares de âmbito social, etc. (Çela, 2015, menciona também a importância das redes sociais), não só não se opõem à visão habermasiana de esfera pública, como também se posicionam na forma de apoio aos princípios e requisitos de um ideal de esfera pública ao nível global, ideia que, segundo o autor, se justapõe às pesquisas mais habituais e conflituais sobre este assunto.

Khan (2012) refere que as condições estruturais para o modelo habermasiano de esfera pública são, em primeiro lugar, o facto de serem as instituições de media a sua grande fundação; segundo, o papel da opinião pública como interveniente crucial e como principal instrumento de vigilância dos Estados; e terceiro, a necessidade imperativa de uma sociedade civil vibrante e capaz de conduzir o debate público. Assim, para Khan (2012), a conceção de esfera pública resulta mais de um modelo em tríade que beneficia das estruturas de participação descentralizada em rede, na Era das novas liberdades de agir e interagir, ao mesmo tempo que o papel fundacional atribuído aos media passa a ser disputado pelo poder cada vez maior do cidadão ativo e participativo em rede, 
sustentado por aquilo a que Crack (2007) designa como o papel determinantemente diferenciador das novas tecnologias e da internet na reformulação do novo modelo de esfera pública em rede.

Contudo, e antes das visões mais celebratórias de Benkler (2006) e Khan (2012) relativamente a um modelo reformulador da conceção normativa de esfera pública, Boeder (2005) declarava que a redefinição do conceito de esfera pública como extensão do alcance e impacto da participação dos cidadãos, acompanhava de certa forma o abandono da distinção rigorosa entre facto e ficção da pós-modernidade. Desta forma, e ao contrário das observações posteriores de Benkler (2006) e Khan (2012), os argumentos de Boeder (2005) realçam a centralidade das instituições de media e do credencialismo profissional na determinação de uma esfera pública válida, mais próxima do conceito inicial de Habermas, em detrimento de um robustecimento do papel atribuído à sociedade civil e à opinião pública na determinação de uma nova esfera pública. Esta ideia de Boeder (2005) é reforçada anos mais tarde por Ahva (2011), autora que enfatiza o papel central do jornalismo enquanto instituição ou agente envolvido na construção da esfera pública, mesmo que não seja despiciendo debater a validade de uma discussão mais maximalista centrada em múltiplas esferas públicas, ao contrário do modelo de esfera pública singular dos primeiros trabalhos de Habermas.

Boeder (2005) questiona-se também sobre a possibilidade de os novos media, como a internet, apenas oferecerem um substituto superficial para aquilo que este designa como "discurso autêntico". O autor interroga-se sobre se serão as comunidades virtuais capazes de contribuir para a renovação do debate público ou se são meras simulações de distração catártica de um público que passa a sentir-se mais envolvido, mesmo que esse envolvimento auto-percecionado não tenha repercussão num avanço e consolidação da participação efetiva.

Neste sentido, e realçando a necessidade de discutir amplamente a redefinição de esfera pública, Boeder (2005) destaca o escasso debate relativamente a algumas condicionantes, como é o caso da falta de discussão sobre questões como a propriedade e controlo da tecnologia (central na discussão sobre uma nova esfera pública em rede), bem como daqueles por ela beneficiada. Boeder (2005) auxilia-se dos contributos iniciais de Fernback e Thomson (1995), autores que concluíam no final da década de 1990, em pleno desenvolvimento da internet, que a cidadania via ciberespaço teria de 1) provar poder ser uma panaceia aos problemas de representação democrática, ao mesmo tempo que a 2) participação ativa, sustentada nos canais múltiplos de publicação e comunicação nos media eletrónicos, poderia não ser necessariamente sinónimo de sociedades mais saudáveis a partir do alargamento do debate público.

Mahlouly (2013), por seu turno, introduz mais debate sobre a construção de um modelo de esfera pública no contexto digital, identificando a emergência de comunidades transnacionais e difusas, mas sustentando-se de um certo determinismo tecnológico, no sentido em que, para a autora, as interações sociais online são primeiramente condicionadas e limitadas pelo desenho tecnológico dos novos dispositivos comunicacionais. Adicionalmente, Mahlouly (2013) tenta demonstrar a forma como a era digital 
afeta a qualidade do discurso público, ao conferir poder aos intervenientes amadores e ao legitimá-lo na mesma exata medida dos profissionais especializados. A autora estabelece assim uma distinção entre a esfera pública normativa e a atual cultura participativa central ao novo modelo de esfera pública, rejeitando a ideia de que todas as pessoas estão aptas a contribuir na mesma exata medida para o discurso público. No entanto, a autora reconhece igualmente os benefícios da tecnologia como veículo de expressão das múltiplas subjetividades, dando o exemplo do ciberativismo, e enfatizando a ideia de que as interações sociais online aumentam a atratividade dos projetos colaborativos e do envolvimento político, ao garantirem aos utilizadores a oportunidade de defenderem a sua identidade individual e poderem fazer parte de um conjunto de movimentos sociais mais alargados.

Em resumo, Ahva (2011, p. 124) fala-nos de uma dicotomia categorial do papel dos cidadãos na esfera pública, enquanto representantes ou agentes ativos da cidadania.

Para a autora, mais próxima da teoria normativa habermasiana de esfera pública, a derradeira autoridade nas sociedades, apesar de ser atribuída aos cidadãos, não determina para os mesmos, através da sua atividade pública, o papel central no funcionamento da esfera pública.

Por contraponto, o enquadramento agencial, mais disruptivo e associado à nova esfera pública global em rede, sugere que os cidadãos constituem o grupo de comunicadores mais importante na determinação de qualquer esfera pública, num modelo que se centra numa participação contínua dos cidadãos e que tem como base o facto de todos os cidadãos serem os especialistas da sua própria vida e dos seus interesses (Walter, 2015).

\section{A PARTICIPAÇÃo PÚBLICA NA REDEFINIÇÃo DA ESFERA PÚBLICA: A PERSPETIVA PORTUGUESA}

A descentralização do processo de produção de notícias na sociedade em rede (Castells, 2002) e na Era das culturas da conectividade (Van Dijck, 2013) redefine as estruturas de poder simbólico no processo de construção das notícias. As organizações de media passam a dispor de menor controlo sobre o conteúdo e sobre a sua distribuição. Como grande consequência, a robustez deste papel abraçado pelos públicos simultaneamente consumidores, produtores, avaliadores e comentadores de notícias, passa a desafiar o papel central atribuído aos média, e ao jornalismo em particular, como elementos fundacionais de uma esfera pública normativa, numa discussão que varia fundamentalmente entre a necessidade de preservar o papel das organizações de media e do jornalismo na construção de uma esfera pública seminal, e a necessidade de refundar a conceção de esfera pública a partir do intrincado sistema de participação e interações globais em rede.

Nas linhas seguintes olhamos com atenção para o que se passa em Portugal, a partir das dinâmicas de participação pública e espaço público no ciberespaço, com o recurso a dados recentes do estudo Digital news report (2018) do Reuters Institute for the Study of Journalism, com a colaboração do Observatório da Comunicação de Lisboa.

As questões que constituem o módulo produzido sobre participação pública na internet, no inquérito Reuters, permitem-nos constatar, desde logo, que aproximadamente 
metade dos inquiridos envolvidos no estudo tende a partilhar notícias e a fazê-lo principalmente por email ou através das redes sociais. Para além disso, cerca de sete inquiridos em cada dez alegam participar em conteúdos informativos na internet, numa amostra que se declara muito ou extremamente interessada em notícias.

Por outro lado, a dimensão de comentário à notícia evidencia um traço distintivo desta amostra de utilizadores de internet que passa por compreender que a partilha de notícias é mais relevante do que o comentário à notícia. Na base desta evidência poderá estar a interpretação de que "as pessoas não criam informação nova por si mesmas, basicamente reproduzem aquilo que lhes chega" (Luque, Martínez \& Sánchez, 2013, p. 67).

Adicionalmente, "a teoria deliberativa propõe diversas condições que as conversas de cidadãos necessitam de satisfazer antes de serem consideradas conversas democráticas e deliberativas" (Barber, Dahlberg \& Stromer-Galley, citados em Strandberg \& Berg, 2013, p. 111), sendo que, para os autores, no caso específico do comentário em sites online de títulos de imprensa, e segundo os dados recolhidos a partir da análise de conteúdo aos comentários produzidos na edição online de um jornal finlandês, os outputs produzidos na forma de participação pública são muitas vezes desprovidos de qualidade (Strandberg \& Berg, 2013, p. 111).

Assim, "apesar de os comentários online permitirem aos cidadãos discutirem os temas em contexto" (Strandberg \& Berg, 2013, p. 113), estes não oferecem muitas vezes as condições para uma reformulação da esfera pública com base na qualidade da participação pública no formato digital, no sentido em que podem representar um conjunto de considerações demagógicas, beligerantes, exibicionistas, subjetivas, pouco racionais, incivilizadas, e conversas de circunstância que não satisfazem as condições normativas de deliberação e da esfera pública (Dahlberg, 2004).

Em última análise, como observa Torres da Silva (2013, p. 83), "apesar de vários estudos sublinharem a vertente democratizadora da Internet, permanecem ainda dúvidas acerca da qualidade dos debates que aí ocorrem".

\begin{tabular}{ll}
\hline Partilhar notícias & $48,8 \%$ \\
\hline Partilhar notícias por email ou via redes sociais & $44,5 \%$ \\
\hline Comentar em peças noticiosas & $29,9 \%$ \\
\hline Participar na internet em conteúdos informativos & $69,5 \%$ \\
\hline
\end{tabular}

Tabela 1: "Numa semana normal, na sua atividade online, costuma..." Fonte: Reuters Institute for the Study of Journalism, 2018

Quando questionados sobre as formas de partilha e participação nos conteúdos noticiosos, verificamos que as modalidades mais mencionadas, por ordem decrescente de importância, são a interação com amigos e colegas na internet; a partilha de notícias numa rede social, como o Facebook ou o Twitter, categoria que evidencia o peso que as redes sociais têm hoje na determinação do ciclo de vida das notícias; e o comentário sobre notícias nas redes sociais. Relativamente ao fenómeno do poder das redes sociais, 
Luque, Martínez e Sánchez (2013, pp. 57-59) lembram-nos que estas surgem como oportunidades reais de protestos individualizados e de massa, veiculados, em grande parte, através de conteúdos gerados pelo utilizador, como resultado de estes se terem transformado nas principais plataformas de organização cívica que permitem a comunicação entre milhões de pessoas.

De salientar ainda que o comentário a notícias nos sites de grupos de imprensa é valorizado apenas por cerca de $9 \%$ dos inquiridos, ao passo que cerca de $18 \%$ dos inquiridos classificam, marcam ou fazem like em notícias.

\begin{tabular}{ll}
\hline Partilho notícia/s numa rede social (Facebook, Twitter, Linkedin) & $35,7 \%$ \\
\hline Partilho notícia/s via email & $17,8 \%$ \\
\hline Classifico, faço like ou marco notícias & $17,6 \%$ \\
\hline Comento notícias nas redes sociais (Facebook, Twitter) & $26,2 \%$ \\
\hline Comento notícias nos sites de grupos de imprensa & $8,7 \%$ \\
\hline Escrevo sobre questões políticas ou noticiosas em blogs & $14,4 \%$ \\
\hline Envio ou partilho vídeos e fotos de cariz informativo em sites de redes sociais & $8,6 \%$ \\
\hline Envio ou partilho vídeos e fotos para sites de grupos de imprensa/organizações de média & $5,4 \%$ \\
\hline Participo em votações online via sites de notícias ou redes sociais & $11,6 \%$ \\
\hline Participo em campanhas ou grupos baseados num assunto noticioso & $3,4 \%$ \\
\hline Interajo com amigos e colegas na internet, sobre notícias (por email, redes sociais, aplicações de mensagens) & $42,3 \%$ \\
\hline Partilho notícias via plataformas de mensagens (Whatsapp, Facebook, Messenger, etc.) & $18,5 \%$ \\
\hline Nenhuma das anteriores & $20,3 \%$ \\
\hline
\end{tabular}

Tabela 2: "Numa semana normal, de que forma partilha ou participa em conteúdos noticiosos?"

Fonte: Reuters Institute for the Study of Journalism, 2018

As dimensões de interacção e partilha de notícias constituem-se assim como duas vertentes importantes do relacionamento dos inquiridos com as notícias, ainda que o comentário às mesmas seja relevado apenas por $1 / 4 \mathrm{da}$ amostra.

O facto de a grande maioria dos inquiridos assinalar pelo menos uma forma de participação ou partilha de notícias online, resulta, por contraponto, em apenas $20,3 \%$ de inquiridos que declaram não partilhar ou participar de nenhuma forma nos conteúdos noticiosos online.

Por outro lado, a Tabela 3 confirma o peso crescente das redes sociais naquilo a que Castells (2007) designou como o ambiente das notícias em rede, e que autores como Bergström e Belfrage, 2018; Carlson, 2017; Mourao et al., 2015; Sampedro e Avidad, 2018; Usha e Niemann, 2017, fazem referência como um dos principais meios transformadores do ecossistema das notícias.

Com efeito, $75 \%$ dos inquiridos utilizam por exemplo o Facebook para uso geral, sendo que, destes, 52,5\% têm por hábito ler, ver, partilhar ou discutir conteúdos 
noticiosos nesta plataforma. Para além disso, e pese embora o facto de a hegemonia do Facebook dentro do segmento das redes sociais em Portugal ser evidente, um grande número de inquiridos tende a utilizar outras plataformas sociais, ainda que, em proporção, o Facebook seja a rede social mais utilizada para interagir com conteúdos noticiosos.

\begin{tabular}{lll}
\hline & Uso GERAL & $\begin{array}{c}\text { LER, VER, PARTILHAR OU DIS- } \\
\text { CUTIR CONTÉ UOS NOTICIOSO }\end{array}$ \\
\hline Facebook & $74,8 \%$ & $52,5 \%$ \\
\hline YouTube & $68,7 \%$ & $22,2 \%$ \\
\hline Facebook Messenger & $62,5 \%$ & $19,4 \%$ \\
\hline WhatsApp & $39,9 \%$ & $11,2 \%$ \\
\hline Instagram & $33,9 \%$ & $6,4 \%$ \\
\hline Linkedln & $24,7 \%$ & $6,7 \%$ \\
\hline Pinterest & $21,4 \%$ & $3,3 \%$ \\
\hline Twitter & $13,1 \%$ & $5,3 \%$ \\
\hline Google+ & $9,6 \%$ & $3,6 \%$ \\
\hline Snapchat & $5,7 \%$ & $0,8 \%$ \\
\hline Tumblr & $3,2 \%$ & $0,6 \%$ \\
\hline Viber & $2,7 \%$ & $0,4 \%$ \\
\hline Telegram & $1,7 \%$ & $0,5 \%$ \\
\hline Flickr & $1,2 \%$ & $0,1 \%$ \\
\hline Slack & $1,2 \%$ & $0,4 \%$ \\
\hline Periscope & $0,7 \%$ & $0,1 \%$ \\
\hline Line & $0,6 \%$ & $0,2 \%$ \\
\hline WeChat & $0,6 \%$ & $0,0 \%$ \\
\hline Kik & $0,3 \%$ & $0,1 \%$ \\
\hline Outra & $1,0 \%$ & $0,7 \%$ \\
\hline
\end{tabular}

Tabela 3: Utilização de redes sociais em geral e para ler, ver, partilhar ou discutir conteúdos noticiosos Fonte: Reuters Institute for the Study of Journalism, 2018

\begin{tabular}{lc}
\hline Postei conteúdos noticiosos & $16,9 \%$ \\
\hline Partilhei ou fiz like numa notícia & $57,1 \%$ \\
\hline
\end{tabular}

Tabela 4: "Ao utilizar o Facebook na semana anterior à realização do estudo, quais as tarefas que desempenhou?"

Fonte: Reuters Institute for the Study of Journalism, 2018 ( $n=1055)$

Dos 1.055 inquiridos que declararam ter utilizado o Facebook na semana anterior à realização do inquérito, mais de metade referem ter partilhado ou feito like em notícias, ao passo que $16,9 \%$ publicam conteúdos noticiosos nas suas páginas de Facebook. Mais uma vez, a dimensão de partilha de algo já publicado ou a circular na rede sobrepõe-se à publicação por iniciativa própria. 


\begin{tabular}{ll}
\hline Concordo & $31,4 \%$ \\
\hline Não concordo, nem discordo & $33,6 \%$ \\
\hline Discordo & $34,9 \%$ \\
\hline
\end{tabular}

\footnotetext{
Tabela 5: “É importante para mim, sempre que procuro por notícias nas redes sociais, ter em atenção o número de likes e partilhas dessas notícias porque são os likes e partilhas que me dizem se a notícia é merecedora do meu tempo"

Fonte: Reuters Institute for the Study of Journalism ( $n=1937)$
}

O contexto da economia da atenção (Davenport \& Beck, 2002) constrói-se e define-se em parte nas métricas de consulta, likes e partilhas nas experiências online de uma parte dos utilizadores de internet. Contudo, e no que respeita à importância dos likes e à partilha na determinação das dietas informativas dos utilizadores online, interessa fazer notar que, muito embora $31,4 \%$ dos inquiridos considerem importante o número de likes na escolha das notícias vistas, $33,6 \%$ dos inquiridos não concordam nem discordam da afirmação, ao passo que cerca de $35 \%$ não veem no número de likes e partilha das notícias uma condição definidora do interesse da notícia.

\begin{tabular}{ll}
\hline Concordo & $36,0 \%$ \\
\hline Não concordo, nem discordo & $34,4 \%$ \\
\hline Discordo & $29,6 \%$ \\
\hline
\end{tabular}

Tabela 6: "Tendo a pensar cuidadosamente quando expresso os meus pontos de vista políticos na Internet, porque isto me pode trazer problemas perante a autoridade"

Fonte: Reuters Institute for the Study of Journalism (n2018=2008)

Uma das razões para o facto de a partilha da notícia ser mais frequente do que o comentário produzido sobre a mesma, poderá ser explicada com base nas motivações descritas na tabela sete. Com efeito, $36,0 \%$ dos inquiridos (mais de um terço da amostra) ainda tendem a pensar e a refletir cuidadosamente nos seus comentários e pontos de vista políticos, na internet, não sendo claro nesta análise se essa reflexão é impeditiva de uma maior participação online por via do comentário produzido, ou se é apenas determinada pela ideia de que as pessoas, ao não criarem informação nova, tendem basicamente a reproduzir aquilo que lhes chega (Luque et al., 2013).

Com base no cruzamento de algumas variáveis sociodemográficas (género, idade e grau de escolaridade) com as questões discutidas nas tabelas anteriores, constatamos que não se registam diferenças significativas em termos de associação entre as variáveis. 


\begin{tabular}{|c|c|c|c|c|c|c|c|c|c|c|c|}
\hline & \multicolumn{2}{|c|}{ GÉNERO } & \multicolumn{5}{|c|}{ IDADE } & \multicolumn{4}{|c|}{ GRAU DE ESCOLARIDADE } \\
\hline & $\begin{array}{l}\text { Mas- } \\
\text { culino }\end{array}$ & $\begin{array}{l}\text { Femi- } \\
\text { nino }\end{array}$ & $18-24$ & $25-34$ & $35-44$ & $45-54$ & $55^{+}$ & $\begin{array}{l}\text { Ensino } \\
\text { secundário } \\
\text { incompleto }\end{array}$ & $\begin{array}{l}\text { Ensino } \\
\text { secundário }\end{array}$ & $\begin{array}{l}\text { Ensino } \\
\text { profissional }\end{array}$ & $\begin{array}{l}\text { Ensino } \\
\text { superior }\end{array}$ \\
\hline $\begin{array}{l}\text { Partilhei notícias } \\
\text { via redes sociais }\end{array}$ & $33,5 \%$ & $37,6 \%$ & $22,8 \%$ & $27,2 \%$ & $32,1 \%$ & $37,3 \%$ & $43,1 \%$ & $36,7 \%$ & $37,1 \%$ & $32,1 \%$ & $35,8 \%$ \\
\hline $\begin{array}{l}\text { Comentei um post } \\
\text { noticioso numa } \\
\text { rede social }\end{array}$ & $26,7 \%$ & $25,7 \%$ & $17,3 \%$ & $19,9 \%$ & $27,5 \%$ & $26,5 \%$ & $30,1 \%$ & $15,9 \%$ & $28,5 \%$ & $23,9 \%$ & $26,4 \%$ \\
\hline $\begin{array}{l}\text { Comentei um post } \\
\text { noticioso num } \\
\text { site noticioso }\end{array}$ & $11,1 \%$ & $6,5 \%$ & $4,6 \%$ & $8,6 \%$ & $8,1 \%$ & $10,5 \%$ & $9,1 \%$ & $6,1 \%$ & $8,2 \%$ & $11,3 \%$ & $8,8 \%$ \\
\hline $\begin{array}{l}\text { Participei em } \\
\text { votações online via } \\
\text { sites de notícias } \\
\text { ou redes sociais }\end{array}$ & $14,2 \%$ & $9,2 \%$ & $8,1 \%$ & $10,0 \%$ & $10,3 \%$ & $14,2 \%$ & $12,7 \%$ & $11,0 \%$ & $9,7 \%$ & $12,6 \%$ & $13,1 \%$ \\
\hline $\begin{array}{l}\text { Interajo com } \\
\text { amigos e colegas } \\
\text { na internet, sobre } \\
\text { notícias (por email, } \\
\text { redes sociais) }\end{array}$ & $25,2 \%$ & $26,4 \%$ & $28,9 \%$ & $23,9 \%$ & $23,5 \%$ & $22,5 \%$ & $28,5 \%$ & $22,0 \%$ & $22,4 \%$ & $20,1 \%$ & $28,8 \%$ \\
\hline $\begin{array}{l}\text { Penso cuidado- } \\
\text { samente quando } \\
\text { expresso os } \\
\text { meus pontos de } \\
\text { vista políticos na } \\
\text { internet, porque } \\
\text { isto me pode trazer } \\
\text { problemas perante } \\
\text { as autoridades }\end{array}$ & $36,6 \%$ & $35,4 \%$ & $37,1 \%$ & $38,2 \%$ & $38,3 \%$ & $34,2 \%$ & $34,7 \%$ & $31,7 \%$ & $36,4 \%$ & $36,5 \%$ & $35,8 \%$ \\
\hline
\end{tabular}

Tabela 7: Algumas análises sociodemográficas às formas de interação e partilha online Fonte: Reuters Institute for the Study of Journalism, 2018 (n2018=2008)

\begin{tabular}{|c|c|c|c|}
\hline MEDIDAS DE ASSOCIAÇÃO & $\begin{array}{c}\text { GÉNERO } \\
\text { (DICOTÓMICA) }\end{array}$ & $\begin{array}{c}\text { IDADE } \\
\text { (ORDINAL) }\end{array}$ & $\begin{array}{l}\text { GRAU DE ESCOLA- } \\
\text { RIDADE (ORDINAL) }\end{array}$ \\
\hline Partilhei notícias via redes sociais (Dicotómica) & Vcramer $=0,043$ & Vcramer $=0,153$ & Vcramer $=0,063$ \\
\hline Comentei um post noticioso numa rede social (Dicotómica) & Vcramer $=0,009$ & Vcramer $=0,102$ & Vcramer $=0,069$ \\
\hline Comentei um post noticioso num site noticioso (Dicotómica) & Vcramer $=0,086$ & Vcramer $=0,058$ & Vcramer $=0,036$ \\
\hline $\begin{array}{l}\text { Participei em votações online via sites de notícias ou redes so- } \\
\text { ciais (Dicotómica) }\end{array}$ & Vcramer $=0,076$ & Vcramer $=0,062$ & Vcramer $=0,070$ \\
\hline $\begin{array}{l}\text { Interajo com amigos e colegas na internet, sobre notícias (por } \\
\text { email, via redes sociais) }\end{array}$ & Vcramer $=0,014$ & Vcramer $=0,059$ & Vcramer $=0,080$ \\
\hline $\begin{array}{l}\text { Penso cuidadosamente quando expresso os meus pontos de } \\
\text { vista políticos na internet, porque isto me pode trazer proble- } \\
\text { mas perante as autoridades (Dicotómica) }\end{array}$ & Vcramer $=0,050$ & Vcramer $=0,054$ & Vcramer $=0,043$ \\
\hline
\end{tabular}

Tabela 8: Cruzamento entre variáveis sociodemográficas e as questões do módulo "As notícias e participação pública"

Fonte: Reuters Institute for the Study of Journalism (n2018=2008) 
Contudo, é possível assumir algumas diferenças percentuais dos valores obtidos, a saber: 1) os inquiridos do sexo masculino tendem a comentar mais em posts noticiosos nos sites de grupos de comunicação e tendem igualmente a participar mais em votações online via sites de notícias ou redes sociais; 2) os inquiridos do sexo feminino e inquiridos situados em escalões etários superiores tendem a partilhar mais notícias via redes sociais; 3) Os inquiridos mais velhos tendem a comentar mais os posts noticiosos nas redes sociais e os inquiridos com o ensino secundário incompleto tendem a fazê-lo menos vezes; 4) os inquiridos com o ensino superior tendem a interagir mais com amigos e colegas na internet, sobre questões de ordem noticiosa; 5) os inquiridos mais velhos e inquiridos com o ensino secundário incompleto tendem a ser menos rígidos relativamente à ideia de que, ao expressarem os seus pontos de vista políticos na internet, poderão vir a ter problemas com as autoridades.

Para explicação destes resultados, podemos observar desde logo que

o fator etário tem um peso relevante enquanto influência na partilha e nos comentários de notícias (...) são os mais velhos quem mais comentam e partilham notícias nas plataformas online. Sabendo que os mais jovens são ávidos utilizadores de media sociais online, esta análise permite aferir que, no que respeita a notícias, não são esses os que influenciam, em maior grau, o fluxo de partilhas e comentários online. Para as notícias nas redes sociais são, efetivamente, os mais velhos que mais partilham. (Cardoso et al., 2017, pp. 56-57).

O facto de serem os mais velhos aqueles que mais partilham e mais interagem com as notícias nas plataformas online, opõe-se num certo sentido à ideia disseminada de que os jovens, ao possuírem práticas universais, como diversos autores parecem sugerir (Frenette \& Vermette, 2013, p. 30), tendem a manifestar-se mais na internet do que os restantes escalões etários, exprimindo as suas próprias identidades, experiências e interesses online (Frenette \& Vermette, 2013, p. 27).

\section{Conclusões}

As características principais da internet potenciaram a redefinição das barreiras entre produtores e consumidores de conteúdos, levando estes últimos a estabelecer-se, cada vez mais, como atores ativos e participativos no processo de produção e disseminação de informação, e no robustecimento de novas formas de participação pública online.

Como referem Dahlberg (2007), Mason (2012) e Palczewiski (2001), os dispositivos digitais geraram novas formas de mobilização social para além dos ecrãs e possibilitaram aos cidadãos o exercer de uma influência crescente nas formas de decisão e do processo democrático, o que levou autores como Sampedro e Avidad (2018) a falarem da construção de uma esfera pública digital como espaço alternativo e contra-hegemónico de participação pública.

Ao longo deste artigo foi-nos possível discutir algumas das características definidoras das dinâmicas de participação pública dos portugueses, com base no relacionamento 
que estes assumem ter com o conteúdo noticioso na esfera digital, em função da partiIha e publicação de notícias, do comentário produzido acerca das mesmas, das votações online, etc.

O artigo começou com uma revisão teórica sobre a conceção de esfera pública e o processo de transição para uma nova esfera pública em rede, tentando refletir sobre as dicotomias teóricas de a) uma corrente que faz a defesa do conceito normativo de esfera pública, no contexto habermasiano da posição hegemónica da experiência e perícia profissionais; e b) uma corrente mais celebratória de uma nova esfera pública em rede, sustentada na maior participação e interação online das culturas participativas (Jenkins, 2006; Lewis, 2012; Singer, 2012), capazes de maximizar as características da internet, como a sua velocidade e alcance global, para se poderem estabelecer, cada vez mais, como membros efetivos de um debate público global mais descentralizado, horizontal e diferenciado.

A Internet possui um grande impacto sobre a forma como as relações de poder se desenrolam na sociedade porque, entre outros fatores, aumenta as possibilidades de participação, permitindo formas de expressão que são menos exigentes (...) para além de serem apelativas (...) a capacidade de interagir instantaneamente com as outras partes, são características das TIC que facilitam a participação. Além disso, as TIC permitem o envolvimento na esfera pública (...) significando que é possível participar na esfera pública a qualquer momento, em qualquer lugar. (Frenette \& Vermette, 2013, p.17)

Com base nos dados do Digital news report de 2018, que, para o contexto português, resultam de uma colaboração entre o Reuters Institute for the Study of Journalism e o OberCom, foi-nos possível compreender a forma como os portugueses exercem hoje a sua participação pública no ciberespaço, com base na sua experiência online e no relacionamento com o material noticioso. Da partilha de notícias, à interação com as mesmas via comentário produzido, nas redes sociais e em sites de grupos de comunicação, ou em votações online, muitas são as modalidades que permitem a uma parte substancial dos utilizadores de Internet em Portugal estabelecer-se como parte integrante de um sistema que antes primava pela unidirecionalidade da relação entre produtor de notícia e consumidor passivo. Como nos lembram Frenette e Vermette (2013, p. 16),

os média sempre funcionaram como um importante elemento de transmissão de informação entre aqueles que detêm o poder e a população em geral; porém, durante muito tempo, a comunicação foi sobretudo unidirecional. Estas transformações recentes (i.e. o acesso imediato às informações, a diversidade de fontes em todo o mundo, a possibilidade de o público intervir, etc.) influenciaram consequentemente a forma como as relações de poder se desenrolam.

Contudo, apesar de estas múltiplas modalidades de participação e relacionamento com as notícias serem hoje parte da experiência online dos utilizadores portugueses, e 
mesmo que a própria dimensão hegemónica da partilha possa, por si só, ser considerada uma extensão ou legitimação de um ponto de vista, os resultados obtidos no inquérito Reuters a uma amostra de 2008 inquiridos mostram que a dimensão de partilha de notícias é consideravelmente superior à dimensão e expressão do comentário e opinião produzidos relativamente às temáticas noticiosas. Na base desta constatação poderá estar a ideia de que as pessoas tendem a reproduzir aquilo que lhes chega, ao invés de criarem informação por si mesmas (Luque et al., 2013, p. 67). Uma parte muito considerável dos inquiridos denuncia mesmo alguma relutância na manifestação dos seus pontos de vista, em função das suas consequências perante a autoridade.

Em relação aos perfis de participação, e apesar de as medidas estatísticas não evidenciarem grandes diferenças, os inquiridos do sexo masculino tendem a comentar e a partilhar ligeiramente mais do que os inquiridos do sexo feminino, em sites de grupos de média, ao passo que os inquiridos do sexo feminino tendem a partilhar e a participar mais do que os homens nas redes sociais. Por outro lado, os inquiridos mais velhos são aqueles que mais comentam nos posts noticiosos nas redes sociais e os inquiridos com menores níveis de escolaridade são aqueles que menos notícias comentam.

De certa forma, os resultados obtidos no inquérito aplicado aos utilizadores portugueses de internet evidenciam comportamentos muito próximos das considerações avançadas por Boeder (2005). Crítico da avaliação da consolidação da participação efetiva das novas esferas públicas, Boeder (2005), referindo-se aos novos formatos de participação na internet, fala de um ecossistema que, apesar de variado nas suas modalidades de participação, não se reflete na estabilização de um nível de participação capaz de consolidar a construção de uma nova esfera pública erguida da maior participação dos cidadãos. O pensamento de Boeder (2005), explanado nos resultados obtidos neste estudo, sugere assim o refrear da ideia mais determinística de que "a esfera pública digital se encontra imersa na atual conjuntura de transformação acelerada e provavelmente de rutura, que influirá certamente no modo de exercer a cidadania na contemporaneidade" (Andrade, 2013, p. 186).

Neste sentido, Luque, Martínez e Sánchez (2013, p. 67) reportam-se à participação pública enquanto sonho longínquo, uma esfera pública em rede não totalmente inclusiva, num contexto em que as TIC mais não fazem do que produzir um efeito placebo em termos da participação dos cidadãos na esfera pública. Para os autores, na base do sonho longínquo está a certeza de que a participação pública dos cidadãos através da tecnologia não ocorre de forma automática e proporcionalmente, ou seja, não basta dispor de equipamento tecnológico e aceder ao mesmo.

Num estudo sobre o envolvimento de jovens adultos na esfera digital, as autoras Frenette e Vermette (2013) vão mais longe e ajudam-nos a enquadrar os resultados explorados neste artigo, aludindo ao intrincado sistema de reconfiguração da esfera pública digital e à impossibilidade de se abraçar o garantismo normativo e celebratório das novas esferas públicas, onde cada um é parte integrante dessa mesma reconfiguração. Para as autoras, apesar de a internet potenciar a liberdade de expressão, não é certa a sua capacidade de incentivar o empoderamento dos cidadãos (Frenette \& Vermette, 
2013, p. 29), o que se explica essencialmente por seis pontos, a saber: 1) apesar de a internet ter permitido a um número mais elevado de pessoas intervir nos discursos públicos correntes, os seus utilizadores não têm as mesmas capacidades, quer técnicas, quer sociais, para tirarem proveito destas oportunidades; 2) apesar das óbvias vantagens da internet em termos de envolvimento na esfera pública, nem todos utilizam ou pretendem utilizar estas oportunidades de forma permanente; 3) por outro lado, as práticas de socialização orientam subtilmente homens e mulheres para diferentes concetualizações do seu papel na construção da esfera pública; 4) o facto de a predominância das trajetórias individuais de auto-interesse relativamente à perspetiva de vida e o papel de cada um na sociedade favorecer a mistura de interesses pessoais com assuntos que dizem respeito à sociedade como um todo; 5) o facto de, por detrás do horizonte democrático dos "todos-participativos", se reproduzir uma distribuição desigual do capital sociocultural; e, por último, 6) o facto de estarmos perante diferentes graus de envolvimento público dos cidadãos, desde o ativismo permanente ao interesse mais vago (Frenette \& Vermette, 2013, pp. 30-35).

Em última análise, mesmo que as novas tecnologias de comunicação sustentadas na internet incluam na sua configuração material, o enorme potencial de participação, interação e produção colaborativa, as verdadeiras consequências dessas mudanças carecem ainda de verificação (Murru, 2013, p. 154-155).

\section{Pistas PARA INVESTigaÇÃo FUtURA}

Uma forma de complementar o estudo anual do Reuters Institute for the Study of Journalism poderá passar por recorrer à realização de focus groups e entrevistas a utilizadores de internet, percebendo de forma mais detalhada as motivações e as dinâmicas de participação pública no ciberespaço, bem como a auto-perceção sobre o impacto e influência da participação online destes utilizadores em processos de decisão. Minimizar-se-iam assim os riscos das leituras unidimensionais produzidas pelo método quantitativo que, segundo Bryman (2004, p. 35), encerra o perigo da generalização para além das margens limitadoras da pesquisa. Seguindo as ideias de Flick, Kardorff e Steinke (2004, p. 9) sobre o método qualitativo, uma abordagem mais intensiva às formas de participação pública em rede permitiria complementar os chamados "dados duros", introduzindo diferenciação e intensificação, e oferecendo um novo referencial na interpretação das relações de cariz estatístico da pesquisa quantitativa do Digital news report.

Por outro lado, seria igualmente interessante confrontar o profissional jornalista, figura central da conceção seminal de esfera pública, com os resultados de estudos futuros que procurem refletir sobre o produto da auto-perceção dos cidadãos relativamente à sua participação na construção de uma nova esfera pública, numa discussão que se funde com o debate mais amplo do gatekeeping e da teoria da ambivalência na profissão de jornalista. 


\section{Agradecimentos}

Este artigo foi escrito com o apoio financeiro da FCT (Fundação para a Ciência e Tecnologia - Portugal), contemplado na bolsa individual de doutoramento com a referência SFRH/BD/131338/2017

\section{REFERÊNCIAS}

Ahva, L. (2011). What is public in public journalism? Estudos de Comunicação, 9, 119-142. Retirado de http:// www.ec.ubi.pt/ec/09/pdf/ECog-2011 Mai-07.pdf

Andrade, P. (2013). Ontologia Sociológica da Esfera Pública Digital: o caso da web 2.o./3.o. Comunicação e Sociedade, 23, 186-201. DOI: 10.17231/comsoc.23(2013).1621

Beckett, C. (2008). Super media - saving journalism so it can save the world. EUA: Blackwell Publishing.

Beckett, C. (2010). The value of networked journalism. Londres: London School of Economics and Political Science.

Benkler, Y. (2006). The wealth of networks: how social production transforms markets and freedom. New Haven: Yale University Press.

Bergström, A. \& Belfrage, M.J. (2018). News in social media. Digital Journalism, 6(5), 583-598. DOI: $10.1080 / 21670811.2018 .1423625$

Boeder, P. (2005). Habermas' heritage: the future of the public sphere in the networked society. First Monday, 10(9). DOI: $10.5210 / \mathrm{fm} . \mathrm{v} 10 \mathrm{ig} .1280$

Bryman, A. (2004). Quantity and quality in social research. Londres e Nova lorque: Routledge.

Bryman, A. (2012). Social research methods Oxford: Oxford University Press.

Carlson, M. (2017). Facebook in the news: social media, journalism, and public responsability following the 2016 trending topics controversy. Digital Journalism, 6(1), 4-20. DOI: 10.1080/21670811.2017.1298044

Carlsson, U. \& Weibull, L. (2018). Freedom of expression in the digital media culture. A study of public opinion in Sweden. Göteborg: Nordicom.

Carvalho, T. \& Casanova, J.L. (2010). Esfera pública, democracia e internet: os bloggers em Portugal. OBS*Observatorio, 4(2), o91-118. DOI: 10.15847/obsOBS422010343

Castells, M. (2002). A sociedade em rede. Lisboa: Fundação Calouste Gulbenkian.

Castells, M. (2007). Communication power and counter-power in the networked society. International Journal of Communication, 1, 238-266. Retirado de http://ijoc.org/index.php/ijoc/article/viewFile/46/35

Castells, M. (2008). The new public sphere: global civic society, communication networks, and global governance. The Annals of the American Academy of Political and Social Science, 616(1), 78-93. DOI: $10.1177 / 0002716207311877$

Çela, E. (2015). Social media as a new form of public sphere. European Journal of Social Sciences Education and Research, 4(1), 195-200. DOI: 10.26417/ejser.v4i1.p195-200

Crack, A. M. (2007). Transcending borders? Reassessing public spheres in a networked world. Globalizations, 4(3), 341-354. DOI: 10.1080/14747730701532427 
Dahlberg, L. (2004). The Habermasian public sphere: a specification of the idealized conditions of democratic communication. Studies in Social and Political Thought, 10, 2-18. Retirado de https://tinyurl. com/ygmpxmjq

Dahlberg, L. (2007). The internet, deliberative democracy, and power: radicalizing the public sphere. International Journal of Media Q Cultural Politics, 3(1), 47-64. DOI: 10.1386/macp.3.1.47/1

Davenport, T. H. \& Beck, J.C. (2002). The attention economy: understanding the New Currency of Business. Boston: Harvard Business Press.

Fernback, J. \& Thompson, B. (1995). Virtual communities: abort, retry, failure? [Post em blogue]. Retirado de http://www.rheingold.com/texts/techpolitix/VCcivil.html

Flick, U., Kardorff, E. V. \& Steinke, I. (2004). What is qualitative research? An introduction to the field. In U. Flick, E. V. Kardorff \& I. A. Steinke (Eds.), Companion to qualitative research (pp. 3-11). Londres: Sage.

Frenette, M. \& Vermette, M.F. (2013). Os jovens adultos e a esfera pública digital. Comunicação e Sociedade, 23, 14-35. Retirado de http://dx.doi.org/10.17231/comsoc.23(2013).1611

Gerhards, J. \& Neidhardt, F. (1991). Strukturen Und Funktionen Modernder Offentlichkeit: Fragestellungen Und Ansätze. [Post em blogue]. Retirado de http://www.polsoz.fu-berlin.de/soziologie/arbeitsbereiche/ makrosoziologie/mitarbeiter/lehrstuhlinhaber/dateien/GerhardsNeidhardt-1990.pdf

Giddens, A. (2000). Runaway world. Nova lorque: Routledge.

Glaser, M. (2010). Citizen journalism: widening world views, extending democracy. In S. Allan (Ed). The Routledge companion to news and journalism (pp. 578-590). Nova lorque e Londres: Routledge.

Glasser, T. L. (ed.) (1999). The idea of public journalism. Nova Iorque: The Guilford Press.

Haas, T. (2007). The pursuit of public journalism: theory, practice and criticism. Nova lorque: Routledge.

Habermas, J. (1968/1989). The structural transformation of the public sphere: an inquiry into a category of bourgeois society. Cambridge: Polity Press.

Habermas, J. (1998). Between facts and norms. Cambridge, MA: The MIT Press.

Hjarvard, S. (2018). Public service in the age of social network media. In G. F. Lowe, H. Van den Bulck \& K. Donders (Eds.), Public service media in the networked society (pp. 59-74). Gothenburg: Nordicom.

Jenkins, H. (2006). Convergence culture: where old and new media collide. Nova lorque: New York University Press.

Khan, M. Z. (2012). From Habermas model to new public sphere: a paradigm shift. Global Journal of Human Social Science, 12(5), 43-51. Retirado de https://globaljournals.org/GJHSS_Volume12/6-From-HabermasModel-to-New.pdf

Lewis, S. C. (2012). The tension between professional control and open participation: journalism and its boundaries. Information, Communication Q S Society, 15(6), 836-866. DOI: 10.1080/1369118X.2012.674150

Luque, S. G., Martínez, J. F. \& Sánchez, M. O. P. (2013). O Movimento 15M. Ações coletivas e voláteis no campo político. Comunicação e Sociedade, 23, 56-68. DOI: 10.17231/comsoc.23(2013).1613

Mahlouly, D. (2013). Rethinking the public sphere in a digital environment: similarities between the eighteenth and the twenty-first centuries. ESharp, 20(6), 1-21. Retirado de https://www.gla.ac.uk/media/ media_279211_en.pdf 
Manning, D. W. (1950). The "gate kepper": a case study in the selection of news. Journalism Quaterly, 27(4), 383-390. Retirado de http://www.aejmc.org/home/wp-content/uploads/2012/og/Journalism-Quarterly1950-White-383-90.pdf

Mason, P. (2012). Why it's kicking off everywhere: the new global revolutions. Londres: Verso Press.

Mourao, R. R., Yoo, J., Geise, S., Araiza, J. A., Kilgo, D. K., Chen, V. Y. \& Johnson, T. (2015). Online news, social media and european union attitudes: a multidimensional analysis. International Journal of Communication, 9, 3199-3222. Retirado de http://ijoc.org/index.php/ijoc/article/view/2990/1480

Murru, M.F. (2013). A interseção entre o "óbvio" e o "público catalisado" através do domínio de mediatização das culturas cívicas. Comunicação e Sociedade, 23, 153-169. DOI: 10.17231/comsoc.23(2013).1619

Noor, R. (2017). Citizen journalism vs mainstream journalism: a study on challenges posed by amateurs. Athens Journal of Mass Media and Communication, 3(1), 55-76. Retirado de https://www. athensjournals. gr/media/2017-3-1-4-Noor.pdf

Palczewiski, C. H. (2001). Cyber-movements, new social movements, and counterpublics. In R. Asen \& D. Brouwer (Eds.), Counterpublics and the state (pp. 161-186). Albany NY: State University of New York Press.

Reuters Institute for the Study of Journalism. (2018). Digital news report. Retirado de http://media. digitalnewsreport.org/wp-content/uploads/2018/06/digital-news-report-2018.pdf?×89475

Rosen, J. (1999). What are journalists for? New Haven: Yale University Press.

Sampedro, V. \& Avidad, M.M. (2018). The digital public sphere: an alternative and counterhegemonic space? The case of Spain. International Journal of Communication, 12, 23-44. Retirado de http://ijoc.org/index. php/ijoc/article/view/6943

Shoemaker, P. J. \& Vos, T.P. (2009). Gatekeeping theory. Nova lorque: Routledge.

Singer, J. B. (2012). The journalist in the network. A Shifting rationale for the gatekeeping role and the objectivity norm. Tripodos: Llenguatge, Pensament, Comunicacio, 23, 61-76. Retirado de http:// openaccess.city.ac.uk/3479/7/The\%20Journalist\%20in\%2othe\%20Network.pdf

Sousa, H., Pinto, M. \& Costa e Silva, E. (2013). Esfera pública digital - fragilidades e desafios: uma introdução. Comunicação e Sociedade, 23, 5-8. DOI: 10.17231/comsoc.23(2013).1609

Strandberg, K. \& Berg, J. (2013). Comentários dos leitores dos jornais online: conversa democrática ou discursos de Opereta virtuais? Comunicação e Sociedade, 23, 110-131. DOI: 10.17231/ comsoc.23(2013).1617

Torres da Silva, M. (2013). Participação e deliberação: um estudo de caso dos comentários às notícias sobre as eleições presidenciais brasileiras. Comunicação e Sociedade, 23, 82-95. DOI: 10.17231/ comsoc.23(2013).1615

Usha, M. R. \& Niemann, M. (2017). Social media as a platform for incessant political communication: a case study of Modi's "clean India" campaign. International Journal of Communication, 11, 3431-3453. Retirado de http://ijoc.org/index.php/ijoc/article/view/6727

van der Haak, B., Parks, M. \& Castells, M. (2012). The future of journalism: networked journalism. International Journal of Communication, 6, 2923-2938. Retirado de http://ijoc.org/index.php/ijoc/article/ view $/ 1750 / 832$

Van Dijck, J. (2013). The culture of connectivity: a critical history of social media. Oxford: Oxford University Press. 
Walter, S. (2015). Three models of the european public sphere. Journalism studies, 18(6), 749-770. DOI: $10.1080 / 1461670 X .2015 .1087815$

\section{NOTA BIOGRÁFICA}

Tiago Lima Quintanilha é doutorando em Ciências da Comunicação no ISCTE-IUL e bolseiro de doutoramento FCT no CIES-IUL - Centro de Investigação e Estudos de Sociologia (ESPP). É licenciado em Sociologia pelo ISCTE-IUL e tem uma pós-graduação em Gestão de Recursos Humanos pela mesma instituição.

Atua nas áreas das Ciências Sociais, com ênfase nas Ciências da Comunicação, ciência aberta e estudos de jornalismo. Foi gestor de uma revista científica internacional, de 2009 a 2016, e investigador no ISCTE-IUL e no Observatório da Comunicação em Lisboa. Colaborou com a Entidade Reguladora para a Comunicação Social (ERC) no estudo "Públicos e Consumos de Média". Colaborou com o Centro de Investigação em Sociologia Económica e das Organizações no ISEG - Instituto Superior de Economia e Gestão, e com o Reuters Institute for the Study of Journalism. É autor de três livros, 12 capítulos de livros, uma dezena de artigos académicos e mais de 65 relatórios de pesquisa e consultoria nas áreas dos media e comunicação.

ORCID: https://orcid.org/0000-0001-9189-481X

Email:Tiago.lima@obercom.pt

Morada: CIES-IUL - Centro de Investigação e Estudos de Sociologia (ESPP), Edifício Sedas Nunes, Av. das Forças Armadas, 1649-026 Lisboa (Portugal)

* Submetido: 12.05.2018

* Aceite: 24.07 .2018 